\title{
The Impact of Graph Slope on Rate of Change Judgments in Corporate Reports
}

\begin{abstract}
The use of graphs to disclose financial information in annual reports represents a significant dimension of financial disclosure management. Statistical graphics studies demonstrate that the accurate visual decoding of a graph is contingent upon the graph's slope parameter. This article reports two related studies into the slope parameter in a financial reporting context. A laboratory experiment indicates that sub-optimal slope parameters produce distorted judgments of corporate performance and an examination of the graphical formatting choices of 240 large U.K. companies indicates material departures from the optimal slope parameter. Policy implications are discussed.
\end{abstract}

Key words: Corporate annual reports; Graphical perception; Slope parameter.

\section{INTRODUCTION}

The management of financial disclosure literature, much of which is based on positive accounting theory, emphasizes the motivations of management (see Watts and Zimmerman, 1986, 1990 for reviews). Company management 'have incentives to represent their company's performance in the best possible light' (Tweedie and Whittington, 1990, p. 97). As a result, the financial reporting process has been described as 'selective financial misrepresentation' (Revsine, 1991). Birnberg et al. (1983) identify biasing (selection of favourable signals) and focusing (enhancement/degradation of aspects of the information set) as types of information manipulation.

Early financial disclosure management studies found strong evidence of management action to influence the basic numbers (see, e.g., Schipper's 1989 review). Disclosure management also includes attempts to manage the interpretation and presentation of data, for example, by burying sensitive data or highlighting good news (Gibbins et al., 1990, p. 129). Such interpretative shading, described as 'framing effects', has been shown to be very powerful in altering the meaning attributed by data users (Tversky and Kahneman, 1981; Bazerman, 1990). This finding extends to financial accounting contexts (Hofstedt, 1972).

Vivien Beattie is Professor of Accounting in the Department of Accounting, Finance and Law, University of Stirling, and Michael John Jones is Professor of Financial Reporting at the Cardiff Business School.

We would like to thank David Butler and Olusegun Wallace for their helpful comments on earlier drafts of this article, which has also benefited from the constructive comments of an anonymous reviewer. 
Gibbins et al. (1992, p. 22) acknowledge that the use of graphs to disclose financial information in annual reports could represent a significant dimension in financial disclosure management. ${ }^{\text {Th }}$ This is particularly true, given the modern, TV commercial, sound-bite philosophy where 40 per cent of readers spend less than five minutes reading the annual report (Squiers, 1989). Private stockholder surveys have shown that this group, which holds 50 per cent of common stock in the U.S. (Clarke and Bostock, 1997), rely on their own financial analysis of the annual report for investment decisions, rather than financial advisers. This self-reliance also seems to be increasing over time (Epstein and Pava, 1993). Moreover, nonexpert users typically tend not to read the financial statements thoroughly, preferring to focus on the summary financial highlights (which are often presented in graphic form) and accounting narratives (Epstein and Pava 1993; Anderson and Epstein, 1996; Bartlett and Chandler, 1997). In these circumstances, there is clearly no time for detailed analysis and hence the view formed of the company's performance will be highly impressionistic. Graphs of financial information, which are visual and capable of rapid 'arm-chair' assimilation, may thus be displacing the use of other, less accessible, quantitative presentation formats in the annual report. Expert users do, however, undertake detailed analysis using the data contained in the financial statements (Lee and Tweedie, 1981; Arnold and Moizer, 1984). Yet they also review the entire annual report and thus their detailed analysis is 'framed' by the preceding graphic and narrative sections.

Regulators are now showing an increasing concern with the annual report package as a whole. For example, in the U.K., the Financial Reporting Council (1999) comments on the importance of the 'surrounds' to the financial statements and the Department of Trade and Industry (2000) has proposed that non-statutory information presented with the statutory information as part of the annual report be subject to an auditor's report. Recently, the U.K.'s Accounting Standards Board (ASB) issued a discussion paper that focuses on ways of improving communication with private shareholders. It recognizes that graphs are a powerful medium of communication and, drawing on suggestions in Beattie and Jones (1998), makes five recommendations regarding the use of graphs in annual reports. These cover selectivity in the graphs shown, selectivity in the length of time series shown, measurement distortion, the need for simple two-dimensional formats and the need for related commentary to be located adjacent to the graphs (ASB, 2000, pp. 28-9).

Presentation format (e.g., graphical versus tabular formats) has been identified as a key information processing variable (Libby and Lewis, 1977, pp. 246-7). The form of display organization and the prominence (i.e., salience) of visual cues clearly affects the way in which decision makers acquire and attend to information (Bettman and Kakkar, 1977; Jarvenpaa, 1989, 1990). However, no conclusion of general applicability has yet emerged since decision task is an important interacting

Articles by Graves et al. (1996) and Preston et al. (1996) extend research into the annual report and accounts beyond its technical accounting components by examining pictorial material. They explore the representational, ideological and constitutive roles of images, thus recognizing that multiple interpretations are possible. 
and contingent variable (Blocher et al., 1986; Kaplan, 1988; Sullivan, 1988; Davis, 1989; DeSanctis and Jarvenpaa, 1989). This article does not seek to explore the optimal presentational format in annual reports, but rather explores optimal graphical form.

In external financial reporting, the communication of information, rather than the analysis of data, is the primary function of graphical display. Such displays potentially enhance communicative effectiveness, given the nature of human perceptual and cognitive processes. Graphs, particularly colour graphs, attract the reader's attention and the reader's memory recall ability is normally better for visual than for numerical or textual information (Leivian, 1980). However, an understanding of the basic principles of graph design and construction is required by preparers and readers if graphs are to exploit fully their communicative potential. Many private shareholders and financial analysts may not possess graphical competency skills. In such circumstances, design and construction issues become of particular importance. Taylor and Anderson (1986) demonstrate that U.S. loan officers gained a more favourable impression of corporate performance than was warranted from misleading graphs.

Importantly, '[i]nformed decisions about how to encode data can be achieved only through an understanding of the visual decoding process, which is called graphical perception. A display method that leads to inefficient visual decoding can prevent important aspects of data from being detected or can lead to distortions in the perception of information' (Cleveland, 1994, p. 20, emphasis in original). These distortions can be systematic. Simcox, for example, notes that graph designers can connotatively weight information 'by manipulating certain aspects of the graph' (1984, p. 486). Consequently, the financial graphs contained in corporate annual reports may be designed and constructed to portray performance favourably.

The emergent graphical perception theory provides the analytical basis for the study of graphical formatting choices in corporate annual reports. A series of studies covering several major countries has found that a significant number of financial graphs exhibited measurement distortion (i.e., the graph's physical measurement is disproportionate to the underlying numbers) (Steinbart, 1989; Beattie and Jones, 1992a, 1992b, 1996, 1998, 1999; Mather et al., 1996, 2000; Courtis, 1997; Frownfelter and Fulkerson, 1998). Moreover, certain other design and construction features (e.g., graph type selected, use of background, directional ordering of time series) appear to be manipulated in order to present corporate performance in the best possible light (Beattie and Jones, 1992a, 1992b; CICA, 1993). ${ }^{2}$

A key feature of graph design which has, however, been neglected is the angle of the graph's trend line (termed the slope parameter). An increase in trend data can be represented graphically by a positive slope of between $0^{\circ}$ and $90^{\circ}$ (relative

\footnotetext{
A number of these studies also investigate the issue of graph selectivity. A recent study by Beattie and Jones (2000) focuses exclusively on selectivity in a time series setting. The authors find that, at both the aggregate and individual company levels, the decision to use key financial variable graphs is associated positively with corporate performance measures and is consistent with the manipulation hypothesis.
} 
to the horizontal) by changing either the graph's height or width (or both). The ratio of graph height to graph width is termed the shape parameter or aspect ratio. Theoretical and experimental studies in graphical perception suggest that accurate judgments are critically dependent upon these two graphical attributes. Although the graphical dimensions accurately reflect the underlying numbers, perceptual impressions are inaccurate. Cleveland and McGill (1987, p. 198) comment on these parameters as follows: 'Their virtue is that they can be manipulated by the maker of a graph' (emphasis in original). They are, however, also potential vices, since they affect the judgment and hence interpretation of the data displayed. Graphic display designers can use such design features to 'invite the reader to draw inferences and to be sensitive to connotations that are not explicitly present' (Simcox, 1984, p. 483).

To date, we are aware of no study which has investigated the impact of graphs contained in annual reports on the related financial judgment processes. In accounting, a variety of judgment processes are performed, depending on the user's needs and their level of financial expertise. Some judgments are formally defined tasks (e.g., the estimation of return, risk assessment, valuation), while others are informal (and perhaps subconscious; e.g., categorization and comparison tasks). These informal, perceptual judgment processes often precede more formal cognitive tasks. In annual reports, graphs typically provide a prominent display of precise, quantitative information that is also provided elsewhere in tables. Thus, the information processing of graphs is likely to rely on visual perceptual processing rather than highly cognitive processing.

The purpose of this article is to investigate graph slope parameters in the specific context of financial reporting. Such a study is innovative, in that it is the first study to undertake a behavioural experiment to investigate the magnitude of graphical effects on perceptions of corporate performance. All prior studies have been confined to documenting actual graphical reporting practices. Graphs are a particularly prevalent feature of modern financial reporting. For example, Beattie and Jones (1997) report that 92 per cent of U.S. and 80 per cent of U.K. leading companies present graphs in their annual report. The present study has four main objectives. First, we analyse the nature and importance of the shape and slope parameters by reviewing the relevant statistical graphics literature. Second, we develop an innovative research design that combines experimental and survey data in an interesting way. We use test materials based on actual financial data to investigate the effect of these parameters upon visual perception using specimen financial graphs in a laboratory setting. Third, we document and analyse the use of slope parameters in graphs of key financial variables in corporate annual reports, based upon a study of 240 U.K. companies' reports, to establish the incidence and magnitude of departures from the $45^{\circ}$ optimal slope parameter. Fourth, we explore the relationship between financial performance and the slope parameter. The experimental and survey data relating to the second and third objectives are related, insofar as population data from annual reports are used to establish the range of experimental manipulations and, in turn, the experimental results are used to interpret the variation in the population data. 
This article thus contributes to our understanding of alternative formats and displays in financial accounting, an area into which Swieringa (1996), a former member of the FASB, has called for more research. He observes that judgments about presentations of financial information are very difficult and research about alternative presentations would be helpful' (p. 5). Swieringa does not explicitly mention graphs, but they are a display format currently in common use.

The remainder of the article is presented in three major sections, followed by a summary and conclusion. The next section outlines relevant studies from the statistical graphics literature on the shape parameter and the visual perception of graph slope and develops two hypotheses. To our knowledge, there is no cognate accounting literature. Methods and results of the laboratory study follow, and we then outline the methods and findings of our empirical study on the use of the shape parameter in U.K. corporate annual reports.

\section{LITERATURE REVIEW AND HYPOTHESES}

The key geometric components of rectilinear coordinate graphs, such as line and column graphs, are the scaled axes and the specifier (typically a column in a column graph) which encodes the data values. When graphs are read, the initial information processing activity is perceptual. Geometric aspects of the graph are judged during the first few seconds (Cleveland and McGill, 1987). Information is visually decoded without recourse to cognitive activities such as scale/label reading. Where the primary function of graphs is presentation, rather than analysis, the visual information processing of graphs is likely to be confined to such elementary perceptual tasks (Beattie and Jones, 1992b, p. 293). In a column graph (the graph type most commonly used to portray key financial variables in corporate annual reports), the shape parameter (or aspect ratio) can be defined as the height of the tallest column specifier divided by the total width spanned by all the column specifiers (Simcox, 1984, p. 487). Figure 1 illustrates an outline graph with a shape parameter of 0.86 . When processing information encoded in rectilinear coordinate graphs, the slope (i.e., angle) of line segments is used to judge the rate of change. Research suggests that we 'mentally construct lines' between the tops of the columns in order to judge change (Hollands and Spence, 1992, p. 321). Of key importance, a change in the shape parameter of a graph changes the slopes of these line segments. The importance of the shape parameter lies in its effect on the reader's ability to accurately decode these slopes. The global slope parameter of a graph is the physical slope of the line joining the midpoints of the top of the first and last columns (in Figure 1 this is 0.17 ). This slope can also be defined as the line's angle with the horizontal (orientation), in this case $9.5^{\circ} .^{3}$ Readers judge these orientations in order to decode information about rate of change (Cleveland, 1994, p. 68).

Figure 1 provides a general illustration of the slope parameter and shows both positive (increases) and negative (decreases) slopes. This study focuses only on graphs with positive line segments. 


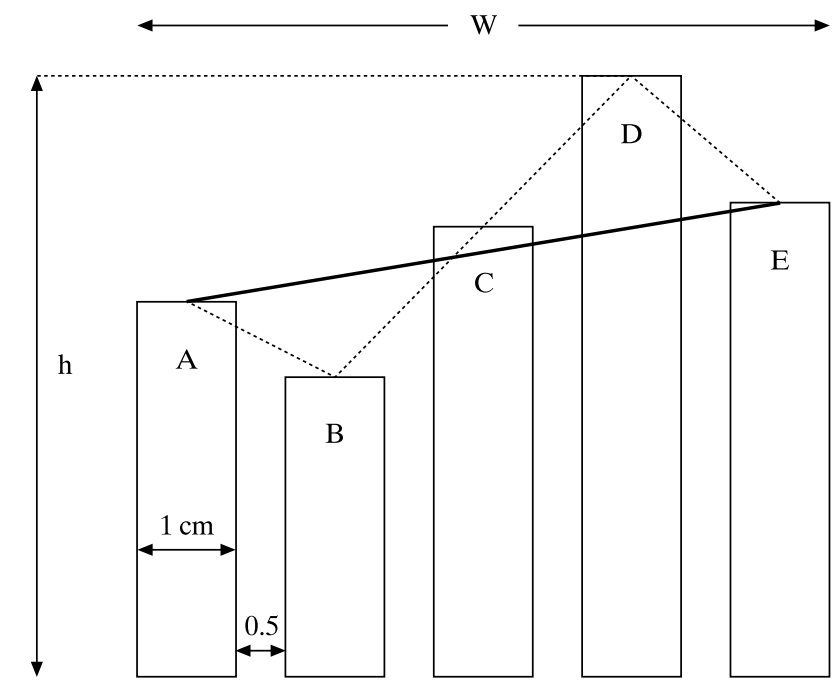

The shape parameter (or aspect ratio) is the height of the tallest column divided by the width spanned by all the columns $(h / w)$, which in this case is $0.86 \mathrm{~cm}$ (i.e., $6 / 7)$. Whereas the line segments on a line graph are explicit (or actual), those on a column graph are implicit. The dotted lines joining the midpoints of the tops of adjacent columns are termed virtual line segments. Their physical slope (angle orientation) is used to judge the local rate of change. Line segments $\mathrm{AB}$ and DE have negative slopes and line segments $\mathrm{BC}$ and $\mathrm{CD}$ have positive slopes. The global slope parameter of the graph can be measured in terms of the physical orientation (i.e., angle) of a line joining the midpoint of the top of columns $\mathrm{A}$ and $\mathrm{E}$, which in this case is $1 / 6=0.17$ or, expressed in degrees, $\arctan (1 / 6)=9.5^{\circ}$.

Figure 2 further illustrates the relationship between graph shape and slope parameters with three outline column graphs each portraying the same five-year time series data. Graphs A, B and C have global slope (shape) parameters of $20^{\circ}(0.62), 45^{\circ}(1.71)$ and $70^{\circ}(4.71)$, respectively. ${ }^{4}$ The evidence from the statistical graphics literature suggests strongly that these three graphs, which encode precisely the same data, will convey very different impressions of the underlying trend, especially to the casual graph user. In particular, graph $\mathrm{C}$ is likely to be perceived as showing stronger growth than either graph A or graph B. Graph B is likely to be judged most accurately. Schmid (1983, pp. 28-9) emphasizes the importance of the shape parameter: 'grid proportions are of pronounced significance as the determinants of the visual impression conveyed'. Thus, it is important to determine the graph shape and slope parameters which will convey the most accurate impression, that is, the optimal parameters.

4 Shape parameters have been varied by manipulating only graph height, rather than either graph width or both height and width. 


\section{Figure 2}

THREE ILLUSTRATIONS OF THE RELATIONSHIP BETWEEN GRAPH SHAPE AND SLOPE PARAMETERS

Time series data used: $10,12,13,15$ and 20 units

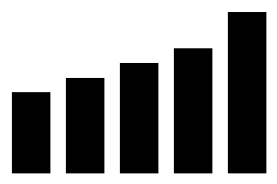

Slope parameter $=20^{\circ}$

Shape parameter $=0.62$ Graph $A$

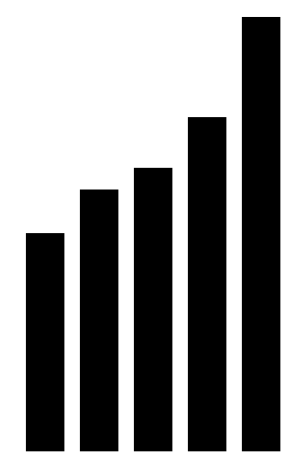

Slope parameter $=45^{\circ}$

Shape parameter $=1.71$ Graph B (optimal)

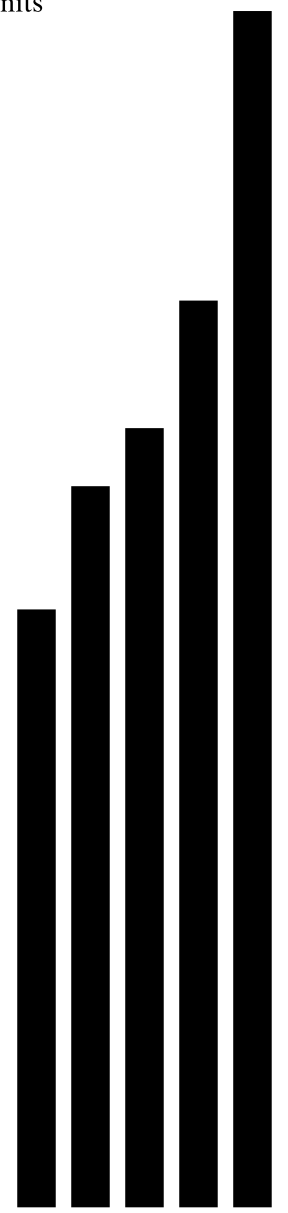

Slope parameter $=70^{\circ}$ Shape parameter $=4.71$ Graph C

A vigorous debate took place throughout much of the twentieth century about the optimal shape parameter and whether it was a fixed ratio or data contingent. ${ }^{5}$ A consensus now appears to have emerged that the optimal slope parameter is approximately $45^{\circ}$ (Bertin, 1983, p. 178; Kosslyn, 1994, pp. 66-7), with the shape

5 Schmid (1983) and Tufte (1983) proposed a fixed ratio, while Von Huhn (1931) and Hall (1958) suggested that an optimal slope should determine the shape parameter. 
parameter being contingent upon this (see, for an example, Figure 2, graph B). Studies by Cleveland and McGill (1987), Cleveland et al. (1988), and Cleveland (1993) use mathematics, the theory of visual perception, and controlled experiments to provide strong theoretical and empirical support for this fundamental principle of graph construction. The experiments employ highly abstract stimuli (typically pairs of line segments with positive slopes) with subjects being asked to judge the slope of one line as a percentage of the other.

Cleveland and McGill (1987) hypothesize that the accuracy of comparative slope judgments is maximized when the average angle of positively sloping line segments is at $45^{\circ} .{ }^{6}$ Cleveland terms this averaging procedure for multiple segments 'banking to $45^{\circ}$ ' (1994, p. 70). Cleveland and McGill's (1987) experimental results reveal that an angle of $+41.1^{\circ}$ (approximating closely to the theoretical optimum) minimized the mean absolute judgment error and conclude that there was 'a decrease in error as the mid-angle gets closer to $45^{\circ}$ ' (p. 202). In other words, the accuracy of slope judgments increased as the slope approaches $+45^{\circ}$. Cleveland et al. illustrate ineffective data displays where the slope parameter diverges from $45^{\circ}$, resulting in inaccurate and biased judgments by the graph reader. Such displays are described as exhibiting orientation distortion (1988, p. 293).

The importance of these findings becomes more apparent when viewed in the overall context of the graph reading process. In general, we do not store precise, quantitative information when reading graphs. Instead, we summarize the essence of the meaning by attaching a linguistic label (such as 'sharply increasing/decreasing') to the graphical information which places it in a specific conceptual category. This procedure allows us to generalize, to compare similar stimuli, and to avoid overloading our information processing system. The meaning of such linguistic labels can be defined empirically using compatibility functions, which locate an implied physical attribute in a corresponding conceptual category. Defined on the interval 0 to 1, 0 indicates no compatibility and 1 indicates complete compatibility. Simcox (1984) uses compatibility functions to map ranges of graph slope parameters for simple line and column graphs onto the conceptual categories 'slightly increasing' and 'sharply increasing'. He finds, for example, that a graph with a $30^{\circ}$ slope is 37 per cent compatible with the conceptual category 'sharply increasing' whereas a $40^{\circ}$ slope is 80 per cent compatible. Moreover, his results indicate that the slope of a line graph must be significantly greater than the slope of a column graph to achieve the same level of compatibility. This result may explain partially the high incidence of column graphs (and dearth of line graphs) used to display key financial variables in corporate annual reports (Beattie and Jones, 1992a), since a column graph will convey the same increasing data trend more favourably than a line graph. Thus, Simcox shows that the slope parameter mediates in the process of applying a linguistic label (conceptual category) to graphical information.

The accuracy with which financial information is decoded from graphs therefore depends fundamentally on the graph's slope parameter, rather than the shape parameter. The optimal slope parameter is $45^{\circ}$ and determines the optimal

${ }^{6}$ The interested reader is referred to Cleveland and McGill $(1984,1985,1987)$ for further detail. 
shape parameter. The studies by Simcox (1984) and Cleveland and McGill (1987) provide the motivation and the theoretical basis of the present two-part study which focuses on the accounting domain. The laboratory study examines the effect of graph slope parameters on the conceptual categorization and perceptual accuracy of trend information concerning financial variables (the slope effect). Our hypotheses (stated in alternative form) are that, ceteris paribus:

H1: In a conceptual categorization task, graphs with larger slope parameters will be categorized as showing greater data increases, and

$\mathrm{H} 2$ : In a comparison task, the graph showing the larger slope parameter will be perceived as showing the more favourable financial performance.

The empirical study of corporate practice investigates the extent to which graph design choices relating to the slope parameter are optimal.

\section{LABORATORY STUDY}

\section{Methods}

Subjects and Stimuli Fifty-three sophomore business studies students, who had completed a one-year course in accounting, participated in the two laboratory experiments, which were administered sequentially. ${ }^{7}$ The experimental stimuli consisted of five-year, time series column graphs of the type commonly found in annual reports. The annual report graphs typically possessed neither a y-axis nor axis labels (see Beattie and Jones, 1992a, pp. 26-7, who report such findings in relation to axes and axes labelling for 154 key financial graphs). Further, only perceptual analysis of the graphs was required since, as argued above, this is the predominant form of processing employed in viewing annual report graphs. Therefore, scale values were omitted to discourage highly cognitive processing, following Simcox (1984).

A set of nine graphs was constructed to reflect each of three levels of two independent variables: slope parameter and overall data increase. All graphs were coloured black, to avoid any confounding perceptual effects relating to colour. Although our primary interest was in the effect of the slope parameter (slope effect) on the conceptual categories used, we introduced a data change effect (data effect) to act as a 'distractor', to minimize learning effects and to investigate the interaction, if any, between the 'slope effect' and the 'data effect'.

\footnotetext{
The studies concerning students as surrogates for managers produce mixed evidence. Whereas some studies show students to be poor surrogates (e.g. Abdel-Khalik, 1974), others such as Remus (1986) and Houghton and Hronsky (1993) are supportive of their use. Remus (1986) points out that a crucial distinction exists between attitudes and decision-making behaviour. While students and managers often have different attitudes, their decision-making behaviour 'often seems to parallel that of managers' (p. 20). He concludes that, in certain decision-making tasks, 'students with little business experience can be safely used as surrogates for managers' (p. 23). Ashton and Kramer (1980) reviewed decision-making studies and found considerable similarities between students and other groups. However, in our view, the experiment in this article has little if anything to do with business decision making, as the task merely requires subjects to apply their graph-reading skills. For this reason, it seemed inappropriate to enlist the cooperation of top managers or users of corporate reports.
} 
The slope parameter levels were set at $30^{\circ}, 45^{\circ}$ (the theoretical optimum) and $70^{\circ}$. The choice of overall data increases was based upon the empirical distribution of the percentage change (over five years) in key financial variables (defined as sales, profit before tax, earnings per share [EPS], and dividends per share [DPS]) reported by the 240 U.K. companies in the second part of our study. The quartiles of this distribution were $61 \%, 111 \%$, and $189 \%$, and we approximated these values to $50 \%, 100 \%$, and $200 \%$. In each of the nine graphs, the overall data increase $(50 \%, 100 \%$, or $200 \%)$ increased monotonically. This was to ensure that all virtual line segments were positive since Cleveland and McGill's (1987) hypothesis relates only to positive line segments. ${ }^{8}$

\section{Procedure}

Subjects were informed that the purpose of the experiment was to examine the effect, if any, of differences in graph structure on perceptions of the data portrayed and that all the graphs to be shown represented time series data of one of four key financial variables frequently reported graphically by companies. The graphic displays presented, and the experimental task, were intentionally kept abstract and simple, in order to focus on the impression conveyed from perceptual analysis of the graph's visual components, in particular graph slope. An example of the graphic displays was shown at the start of the experiment (Appendix A). The instructions to subjects were given in writing and were worded in as neutral a manner as possible in order to reduce the likelihood of subjects guessing the specific experimental hypothesis and answering in line with the researchers' expectations. Two experiments were conducted, comprising nine and thirty-six trials, respectively. On a given trial, the graphic display was projected on to an overhead screen for a fixed duration of three seconds. This short display time was selected, following Cleveland and McGill (1987), in order to prevent highly cognitive processing.

\section{Experimental Tasks and Results}

Experiment One: Categorization Experiment one, designed to test $\mathrm{H} 1$, was a $3 \times 3$ factorial design with slope and data increases as the two independent variables taking the three previously explained values. ${ }^{9}$ Subjects were shown each of the nine graphical stimuli in random order sequence and asked to select (by circling the appropriate response on a data collection sheet) the term which, in their opinion, best described the information portrayed. The five response categories were 'very slightly increasing', 'slightly increasing', 'moderately increasing', 'sharply increasing' and 'very sharply increasing', coded 1 to 5, respectively. Graphs with larger data increases were naturally expected to be categorized as showing greater data increases (the data effect).

8 After this experiment was conducted, Cleveland removed the restriction to positive line segments, arguing that the principle 'is a universal one' which 'applies to the judgment of orientation of any collection of line segments' $(1994,72)$.

9 The shape parameter is not included as an experimental variable since the slope parameter and data values jointly determine the shape parameter. 
FIGURE 3

EXPERIMENT ONE: ANOVA AND DATA CHANGE-RESPONSE FUNCTIONS

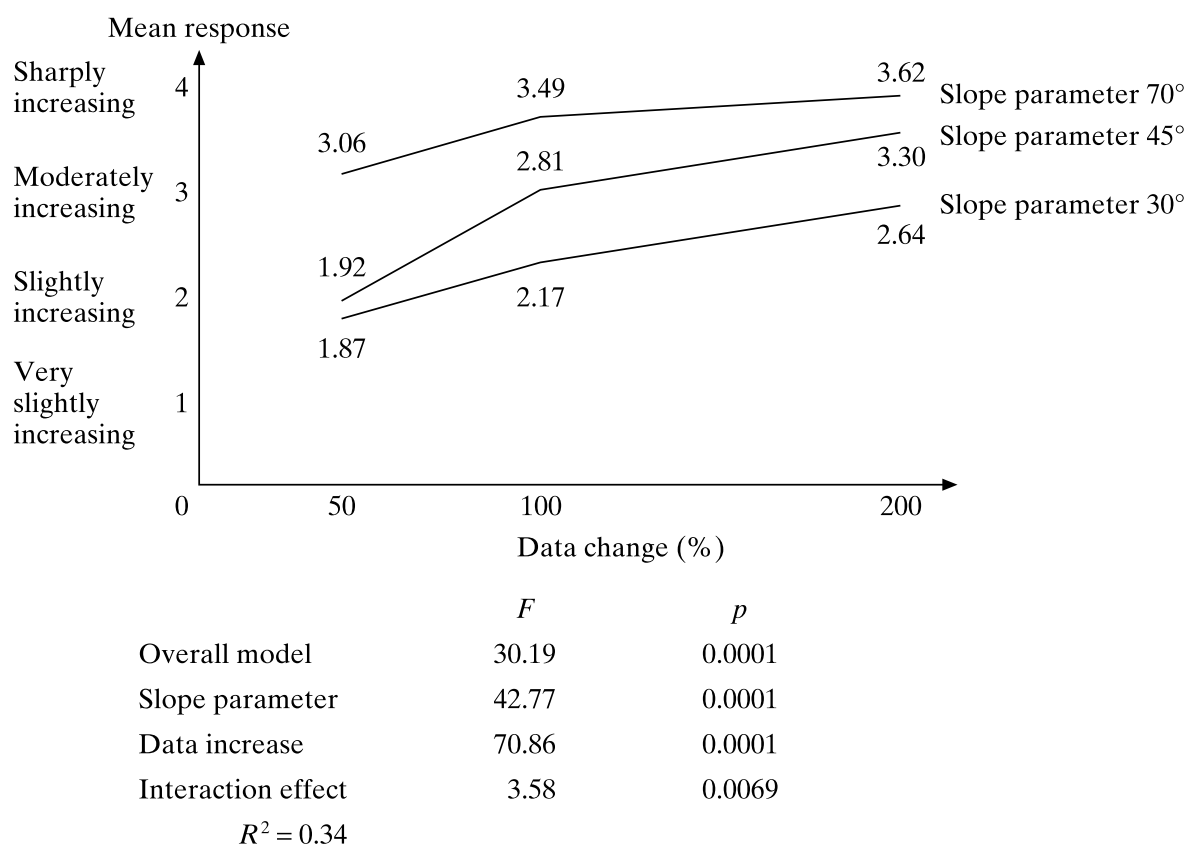

This experiment combines the idea of conceptual categories (Simcox, 1984) with the graph slope experiment of Cleveland and McGill (1987). It builds on Simcox (1984) by asking subjects to select (from a choice of five ordinal categories) the most appropriate conceptual category. By contrast, Simcox offers subjects a dichotomous choice, that is, whether or not they agree with a specified conceptual category. Moreover, we apply Simcox's abstract theoretical model to the realworld financial reporting context.

Analysis of variance (ANOVA) was used to analyse the results. The overall ANOVA model was significant $(F(8,468)=30.19, p<0.0001)$, as were the two independent variables (slope and data increase, $p<0.0001$ ) and the interaction effect $(p<0.01){ }^{10}$ The model explained 34 per cent of the total variation in responses. The results are reported in Figure 3, which also illustrates the data change-response function for each level of slope parameter.

Figure 3 shows that, as expected, the overall mean response is higher for higher levels of data change, indicated by the upward slope of each of the three lines. As hypothesized, the higher slope parameters generally produce higher responses, at

10 While the significance of the interaction term is markedly lower than either of the main effects, it nevertheless suggests that slope parameter and data change have a positive reinforcement effect. 
each level of data change. The $45^{\circ}$ slope parameter gradient is the steepest. At this slope parameter, subjects perceived a 50 per cent data change to be 'slightly increasing' (mean response 1.92), whereas a 200 per cent data change was perceived as 'moderately increasing' (mean response 3.30). In comparison, perceptions of the $30^{\circ}$ and $70^{\circ}$ slope parameter graphs changed less substantively, from 'slightly increasing' (mean response 1.87) to 'slightly/moderately increasing' (mean response 2.64) and from 'moderately increasing' (mean response 3.06) to 'moderately/sharply increasing' (mean response 3.62), respectively. This implies that the subjects were better able to distinguish data variation at a slope parameter of $45^{\circ}$, which is consistent with the view that optimal judgments are made at this level (Cleveland and McGill, 1987). Tukey's studentized range (HSD) pairwise comparison procedure was used on the slope effect variable (SAS Institute, 1989, p. 222). A statistically significant difference existed between the means of the slope effects for each of the three pairs of data change levels (i.e., 50 per cent with 100 per cent, 50 per cent with 200 per cent, and 100 per cent with 200 per cent). Hypothesis H1 is thus supported. Graphs with larger slope parameters were categorized as showing greater data increases.

\section{Experiment Two: Comparison}

In experiment two, designed to test $\mathrm{H} 2$, each trial consisted of a pair of graphs. The nine graphs in experiment one generated thirty-six unique pairings in experiment two (ignoring identical pairs and the order of presentation). These thirtysix pairings were presented in random order. Subjects were informed that each pair of graphs represented two firms' (A and B) financial performance over time. Subjects were once more asked to indicate an appropriate response category. The five response categories were, 'A much more favourable than B', 'A more favourable than B', 'A and B equally favourable', 'B more favourable than $A$ ' and 'B much more favourable than $A$ ', coded 1 to 5 , respectively. The graph showing the larger data increase was naturally expected to be perceived as showing the more favourable financial performance (the data effect).

This experiment involves a comparison task. We are aware of no other study of graphical perception that involves judgments of this or any other kind. In accounting decision making, inter-company comparisons are a common task.

Initial analysis of results using ANOVA showed the overall model of comparative judgments to be significant $(F=5.65, p<0.0001)$, as were the two independent variables (slope difference and data difference) and the interaction effect (all at $p<0.0001$ ). Thus, subjects' perceptions of the relative financial performance of the two firms was influenced by both slope parameter and data difference, both separately and jointly. Subsequent analysis uses paired comparisons to isolate the cause of these effects and explain the interaction effect. In particular, we sought to isolate the effect of the slope parameter upon perceptions.

The following three steps were carried out:

1. The thirty-six trials were organized into a triangular matrix (Table 1). The graph with the greater data increase is shown as graph $\mathrm{A}$. 
2. The nine critical trials which compare graphs with the same data increases, but different slope parameters were isolated. This tests the slope effect hypothesis (Table 2).

3. The nine trials where graphs A and B had the same slope parameters, but different data increases (termed trial group X), were matched with the eighteen trials where graphs A and B had identical slope and data changes to the graphs in trial group X, except for graph B's slope parameter (termed trial group Y). These matched trials allow the interaction of the slope effect and the data effect to be explored (Appendix B).

The responses for each of the thirty-six trials are shown in the form of a triangular matrix in Table 1. In nine trials, the data increases of graphs A and B were identical at either 50 per cent, 100 per cent or 200 per cent (one asterisk), in nine trials the slope parameters of graphs A and B were identical at either $30^{\circ}, 45^{\circ}$ or $70^{\circ}$ (two asterisks), and in the remaining eighteen trials both the data increases and slope parameters of graphs A and B differed (no asterisks). ${ }^{11}$ We have numbered the trials 1 to $36 .{ }^{12}$ Mean responses (and standard deviations) are shown in the cells of Table 1. A mean response of three (the theoretical maximum in the absence of a slope effect) represents no difference in subjects' perceptions of the financial performance portrayed in the two graphs A and B. The expected mean responses will be three or less in all cases, since graph $\mathrm{A}$ has, in all cases, an equal or greater data increase than graph B (see footnote 11) and the data effect is hypothesized to dominate the slope effect. As the mean responses diverge from three, so the difference in subjects' perceptions increases. For example, a mean response of one would indicate that graph A was much more favourably perceived than graph B.

The mean responses reported in Table 1 are three or less, as expected, in thirtytwo out of thirty-six trials, that is, graph A was perceived as more favourable than graph B. ${ }^{13}$ The lowest mean response (of 1.98) occurs, as expected, in the bottom left hand corner cell where the two graphs are most different in both data and slope (graph A: 200 per cent, $70^{\circ}$; graph B: 50 per cent, $30^{\circ}$ ). In this case, both the data effect and the slope effect are at their greatest.

Within the thirty-six trials, there are nine critical trials where graphs A and B have the same data increase, but, crucially, have different slope parameters (indicated by one asterisk in Table 1). In the absence of both a data effect and a slope

11 To facilitate the presentation and analysis of our results, we have standardized responses on the basis that the graph showing the more favourable financial performance (i.e., the graph with the larger data increase) is presented first in Table 1 (graph A) (where data increases for both graphs were identical, the larger slope parameter is presented first).

12 To achieve this, where the graph showing the more favourable financial performance was presented second, responses were recoded as ' 6 minus response', to maintain the 1 to 5 scale values, and the data change and slope parameters of both graphs were reversed.

13 The four cases where the mean response is greater than three lie close to the main diagonal, where the data change and/or slope parameters of the two graphs are not markedly different. For example, trial 10, where the mean response was 3.08 (graph A: 100 per cent, $45^{\circ}$; graph B: 50 per cent, $30^{\circ}$ ). 
TABLE 1

EXPERIMENT TWO: DESCRIPTIVE DATA ON THE 36 COMPARISON TASK TRIALS: STANDARDIZED MEAN RESPONSES (SD)

\begin{tabular}{|c|c|c|c|c|c|c|c|c|c|c|c|}
\hline & \multirow{3}{*}{ Data increase } & \multirow[b]{3}{*}{ Slope parameter } & \multicolumn{9}{|c|}{ Graph B } \\
\hline & & & \multicolumn{3}{|c|}{$50 \%$} & \multicolumn{3}{|c|}{$100 \%$} & \multicolumn{3}{|c|}{$200 \%$} \\
\hline & & & $30^{\circ}$ & $45^{\circ}$ & $70^{\circ}$ & $30^{\circ}$ & $45^{\circ}$ & $70^{\circ}$ & $30^{\circ}$ & $45^{\circ}$ & $70^{\circ}$ \\
\hline & & $30^{\circ}$ & & & & & & & & & \\
\hline & $50 \%$ & $45^{\circ}$ & $\begin{array}{l}{ }^{1} 2.85^{*} \\
(0.63)\end{array}$ & & & & & & & & \\
\hline & & $70^{\circ}$ & $\begin{array}{l}{ }^{2} 2.81 * \\
(0.79)\end{array}$ & $\begin{array}{l}{ }^{3} 2.94 * \\
(0.74)\end{array}$ & & & & & & & \\
\hline & & $30^{\circ}$ & $\begin{array}{l}{ }^{4} 2.81 * * \\
(0.96)\end{array}$ & $\begin{array}{l}{ }^{5} 3.00 \\
(0.78)\end{array}$ & $\begin{array}{l}{ }^{6} 3.02 \\
(1.18)\end{array}$ & & & & & & \\
\hline \multirow[t]{5}{*}{ Graph A } & $100 \%$ & $45^{\circ}$ & $\begin{array}{l}{ }^{7} 2.40 \\
(0.72)\end{array}$ & $\begin{array}{l}{ }^{8} 2.70 * * \\
(0.75)\end{array}$ & $\begin{array}{l}{ }^{9} 2.79 \\
(0.96)\end{array}$ & $\begin{array}{c}{ }^{10} 3.08 * \\
(0.90)\end{array}$ & & & & & \\
\hline & & $70^{\circ}$ & $\begin{array}{c}{ }^{11} 2.32 \\
(0.89)\end{array}$ & $\begin{array}{c}{ }^{12} 2.34 \\
(0.82)\end{array}$ & $\begin{array}{c}{ }^{13} 2.66^{* *} \\
(0.92)\end{array}$ & $\begin{array}{c}{ }^{14} 2.55^{*} \\
(0.89)\end{array}$ & $\begin{array}{c}{ }^{15} 2.66 * \\
(0.78)\end{array}$ & & & & \\
\hline & & $30^{\circ}$ & $\begin{array}{c}{ }^{16} 2.68^{* * *} \\
(1.17)\end{array}$ & $\begin{array}{l}{ }^{17} 2.60 \\
(0.93)\end{array}$ & $\begin{array}{c}{ }^{18} 3.00 \\
(1.11)\end{array}$ & $\begin{array}{c}{ }^{19} 2.58 * * \\
(0.77)\end{array}$ & $\begin{array}{c}{ }^{20} 2.91 \\
(1.00)\end{array}$ & $\begin{array}{c}{ }^{21} 3.28 \\
(1.34)\end{array}$ & & & \\
\hline & $200 \%$ & $45^{\circ}$ & $\begin{array}{c}{ }^{22} 2.34 \\
(1.00)\end{array}$ & $\begin{array}{l}{ }^{23} 2.40 * * \\
(1.05)\end{array}$ & $\begin{array}{l}{ }^{24} 2.85 \\
(1.13)\end{array}$ & $\begin{array}{c}{ }^{25} 2.79 \\
(1.03)\end{array}$ & $\begin{array}{l}{ }^{26} 2.91 * * \\
(0.86)\end{array}$ & $\begin{array}{c}{ }^{27} 3.08 \\
(0.96)\end{array}$ & $\begin{array}{r}28.71 * \\
(0.77)\end{array}$ & & \\
\hline & & $70^{\circ}$ & $\begin{array}{c}{ }^{29} 1.98 \\
(1.08)\end{array}$ & $\begin{array}{c}{ }^{30} 2.34 \\
(1.14)\end{array}$ & $\begin{array}{c}{ }^{31} 2.34 * * \\
(1.13)\end{array}$ & $\begin{array}{c}32.45 \\
(1.10)\end{array}$ & $\begin{array}{c}{ }^{33} 2.45 \\
(0.99)\end{array}$ & $\begin{array}{l}{ }^{34} 2.83 * * \\
(1.03)\end{array}$ & $\begin{array}{l}{ }^{35} 2.60 * \\
(0.93)\end{array}$ & $\begin{array}{c}{ }^{36} 2.56^{*} \\
(0.96)\end{array}$ & \\
\hline
\end{tabular}

Notes: Nine graphs shown as pairs (A and B) to 53 subjects.

One (two) asterisks indicates trials where both graphs have the same data increase (slope parameter).

Response categories were: 1 = A much more favourable financial performance than B; $2=\mathrm{A}$ more favourable financial performance than B; $3=\mathrm{A}$ and $B$ equally favourable financial performance.

The numbers in the top left hand corner of each cell represents a trial number, allocated for cross-reference with Table 2 and Appendix B. 
TABLE 2

EXPERIMENT TWO: $T$-TESTS OF THE SLOPE EFFECT

\begin{tabular}{lrccccc}
\hline $\begin{array}{l}\text { Trial no. from } \\
\text { Table 1 }\end{array}$ & $\begin{array}{c}\text { Data } \\
\text { change }\end{array}$ & $\begin{array}{c}\text { Graph A's } \\
\text { slope parameter }\end{array}$ & $\begin{array}{c}\text { Graph B's } \\
\text { slope parameter }\end{array}$ & $\begin{array}{c}\text { Difference } \\
\text { in slope }\end{array}$ & $t$-statistic & Prob. \\
\hline 1 & $50 \%$ & $45^{\circ}$ & $30^{\circ}$ & $15^{\circ}$ & -1.738 & $0.044^{*}$ \\
10 & $100 \%$ & $45^{\circ}$ & $30^{\circ}$ & $15^{\circ}$ & 0.614 & 0.271 \\
28 & $200 \%$ & $45^{\circ}$ & $30^{\circ}$ & $15^{\circ}$ & -2.679 & $0.005^{* *}$ \\
3 & $50 \%$ & $70^{\circ}$ & $45^{\circ}$ & $25^{\circ}$ & -0.553 & 0.291 \\
15 & $100 \%$ & $70^{\circ}$ & $45^{\circ}$ & $25^{\circ}$ & -3.157 & $0.001^{* *}$ \\
36 & $200 \%$ & $70^{\circ}$ & $45^{\circ}$ & $25^{\circ}$ & -3.328 & $0.001^{* *}$ \\
2 & $50 \%$ & $70^{\circ}$ & $30^{\circ}$ & $40^{\circ}$ & -1.748 & $0.043^{*}$ \\
14 & $100 \%$ & $70^{\circ}$ & $30^{\circ}$ & $40^{\circ}$ & -3.707 & $0.000^{* *}$ \\
35 & $200 \%$ & $70^{\circ}$ & $30^{\circ}$ & $40^{\circ}$ & -3.112 & $0.001^{* *}$ \\
\hline
\end{tabular}

* Significant at 0.05 (one-tailed).

** Significant at 0.01 (one-tailed).

Note: These data are based on 9 of the 36 trials where the data increase was common for graphs A and B (i.e., no data effect). The slopes of graphs A and B differed, thus enabling a direct test of the slope effect.

effect, the expected mean response will equal three. However, in the absence of a data effect and the presence of a slope effect, the expected mean response is less than three. $T$-tests were performed to ascertain whether or not differences in slope parameter had indeed caused differences in the perception of financial performance (i.e., mean response significantly less than three). The results are shown in Table 2. Mean responses were below three at the 0.01 significance level in five out of nine trials, and below three at the 0.05 significance level in a further two trials, consistent with the presence of a slope effect. Interestingly, the greater the difference in slope parameter, the greater the slope effect. Four of the five most significant $t$-tests occurred for slope differences of $25^{\circ}$ and $40^{\circ}$. Thus hypothesis $\mathrm{H} 2$ is supported. Graphs showing larger slope parameters were perceived as showing the more favourable financial performance. In addition, these results indicate that the slope effect appears to be strongest at the higher levels of data change. For example, three out of the five instances of 0.01 level significance occur when the data change was 200 per cent. Thus, the slope effect and the data effect are mutually reinforcing.

The results from experiment two were rearranged into eighteen (two sets of nine) planned matched trials, with each trial, $\mathrm{X}$ and $\mathrm{Y}$, constituting a comparison of two graphs, A and B (see Appendix B). The trials were matched in such a way that, although graphs A and B portrayed different data changes, the data changes involved in trials $\mathrm{X}$ and $\mathrm{Y}$ were identical. The slope parameter for graph A was also identical in both trials. The critical point of difference between the two trials was, thus, the slope parameter of graph B. This allowed us to investigate the interaction of slope and data effects. 
In seventeen out of eighteen comparisons, we found a slope effect, with nine out of the eighteen mean differences being significant. Four of the significant comparisons occurred where the slope parameter difference between graphs A and $\mathrm{B}$ was at the maximum absolute level of $40^{\circ}$, and a further three occurred at the $25^{\circ}$ absolute level. In addition, three of the significant comparisons occur where the data change difference was at the minimum level of 50 per cent. These results suggest that the strength of the slope effect is related directly to the slope parameter differential and weakly inversely related to the data change differential.

The finding that the slope effect is related directly to the slope parameter difference provides evidence, in addition to experiment one, that the slope parameter affects judgments of financial performance. The additional finding that this influence decreases as the data change difference increases provides evidence of a key contingent variable. Thus, we should be most concerned about the impact of variation in slope parameters in comparison tasks involving similar trends. Given that companies' performance trends tend to move together, due to the influence of the economic cycle, this situation is likely to be encountered frequently. So, if company A and company B both perform similarly over a five year period, and company A graphs this trend with a slope parameter of $70^{\circ}$ while company B uses $30^{\circ}$, then performance will be perceived as quite different, even though they are, in fact, very similar.

\section{CORPORATE PRACTICE}

\section{Descriptive Data}

Methods Two hundred and fifty companies were sampled (by selecting every second company) from the largest 500 listed U.K. companies as at 31 March 1989. The corporate annual reports of 240 of these companies were obtained. ${ }^{14}$ These reports contained 456 graphs of key financial variables. ${ }^{15}$ The vast majority of graphs (90 per cent) were of the generic column type (i.e., columns, symbols used as columns, or lines). Bar graphs were excluded from the analysis as the concept of slope parameter is not meaningful for them, leaving 410 graphs. Each of these key financial graphs was measured to enable the calculation of the slope parameter. We restricted our analysis of the slope parameter to the 89 per cent of cases $(364$ graphs) where all the virtual line segments were positive, since Cleveland and McGill's (1987) original hypothesis and experimentation relates only to positive line segments.

14 Seventy-nine per cent of the 240 reports examined had graphs, the average number of graphs being 5.9; 65 per cent of the 240 reports had graphs of one or more of the key financial variables.

15 Seventy-two per cent of the graphs showed a five-year trend. Nineteen graphs had non-zero intercepts. Nine graphs whose specific design features rendered the shape and slope parameters either immeasurable or meaningless (e.g., zero base line obscured, bar graph, pictogram) were eliminated from the analysis. The graphs studied were spread fairly evenly across the four key financial variables: 20 per cent were sales, 28 per cent profit before tax, 27 per cent EPS, and 25 per cent DPS. Graphs of these topics were selected because they were the most frequently reported aggregate financial performance variables, representing 31 per cent of all graphs; a further 28 per cent were graphs of segmental data, with the remaining 41 per cent covering a wide range of financial and nonfinancial measures. 
FREQUENCY DISTRIBUTION OF KEY FINANCIAL VARIABLE GRAPHS' SLOPE PARAMETERS

\begin{tabular}{|c|c|c|c|c|c|c|c|c|c|c|}
\hline & \multirow{2}{*}{$\begin{array}{c}\text { Sales } \\
\text { No. }\end{array}$} & \multirow{2}{*}{$\begin{array}{c}\text { Profit } \\
\text { before } \\
\text { tax } \\
\text { No. }\end{array}$} & \multirow{2}{*}{$\begin{array}{l}\text { EPS } \\
\text { No. }\end{array}$} & \multirow{2}{*}{$\begin{array}{c}\text { DPS } \\
\text { No. }\end{array}$} & \multicolumn{2}{|c|}{ Total } & \multicolumn{2}{|c|}{$\begin{array}{c}\text { Below } \\
\text { median } \\
\text { data change }\end{array}$} & \multicolumn{2}{|c|}{$\begin{array}{l}\text { Above } \\
\text { median data } \\
\text { change }\end{array}$} \\
\hline & & & & & No. & $\%$ & No. & $\%$ & No. & $\%$ \\
\hline $80^{\circ}$ to $\leq 90^{\circ}$ & 1 & 2 & 2 & 2 & 7 & 2 & 4 & 2.2 & 3 & 1.6 \\
\hline $70^{\circ}$ to $\leq 80^{\circ}$ & 3 & 3 & 3 & 3 & 12 & 3 & 5 & 2.7 & 7 & 3.8 \\
\hline $60^{\circ}$ to $\leq 70^{\circ}$ & 7 & 19 & 16 & 9 & 51 & 14 & 20 & 11.0 & 31 & 17.0 \\
\hline $50^{\circ}$ to $\leq 60^{\circ}$ & 16 & 17 & 13 & 9 & 55 & 15 & 23 & 12.6 & 32 & 17.6 \\
\hline $40^{\circ}$ to $\leq 50^{\circ}$ & 10 & 23 & 14 & 18 & 65 & 18 & 36 & 19.9 & 28 & 15.5 \\
\hline $30^{\circ}$ to $\leq 40^{\circ}$ & 16 & 16 & 20 & 18 & 70 & 19 & 36 & 19.8 & 34 & 18.7 \\
\hline $20^{\circ}$ to $\leq 30^{\circ}$ & 9 & 10 & 16 & 20 & 55 & 15 & 27 & 14.8 & 28 & 15.4 \\
\hline $10^{\circ}$ to $\leq 20^{\circ}$ & 8 & 7 & 7 & 17 & 39 & 11 & 25 & 13.7 & 14 & 7.7 \\
\hline $0^{\circ}$ to $\leq 10^{\circ}$ & 1 & - & - & 9 & 10 & 3 & 6 & 3.3 & 5 & 2.7 \\
\hline Total & 71 & 97 & 91 & 105 & 364 & 100.0 & 182 & 100.0 & 182 & 100.0 \\
\hline
\end{tabular}

\section{Results and Discussion}

Although the mean slope parameter (see Table 3) conformed closely to the proposed optimal overall graph slope of $+45^{\circ}$ (Cleveland and McGill, 1987; Cleveland et al., 1988), dispersion was wide, indicating extensive and significant departures from the optimum. The mean overall slope parameter of the 364 graphs was $+42.3^{\circ}$. The frequency distributions for sales, profit before tax, and EPS were similar (and exceedingly close to the $45^{\circ}$ optimum); the distribution for DPS graphs was lower at $+36^{\circ}$. Only 65 ( 17.9 per cent) of the slope parameters were in the band $40^{\circ}$ to $50^{\circ}$, i.e., within $5^{\circ}$ (equivalent to 11 per cent) of the optimal overall slope parameter. Moreover, 174 graphs (47.8 per cent) deviated more than $15^{\circ}$ from the optimal overall slope parameter. Turning to the individual key financial variables, profit before tax graphs showed the least dispersion from $45^{\circ}$, while DPS graphs showed the most. Therefore although, on average, graphs of key financial variables display slope parameters approximating to Cleveland and McGill's (1987) optimal slope of $45^{\circ}$, the majority of individual graphs depart materially from this value. Such extreme slopes impair users' judgmental accuracy and hence their ability to correctly evaluate trend data.

The final four columns of Table 3 report separate analyses for companies with below and above median data change for the key financial variables. As would be expected, companies with below average performance trends generally have graphs with lower slope parameters and vice versa. However, many high performing companies use below median graph slopes, suggesting prima facie that a 
significant proportion of companies either do not control the slope parameter or do not understand its impact.

We explored both the overall association between financial performance and the slope parameter and the association for separate groups of 'poor' performance companies and 'good' performance companies, since the strength of the incentives to manipulate the slope parameter is expected to be greater for the poor performance group. The overall association was investigated for each of the four key financial variable column graphs where all virtual line segments were positive, by calculating the trend (percentage increase) in the key financial variable. As expected, we observed an overall positive relationship between the slope parameter and the percentage increase in the time series data (since greater data increases result inevitably in higher slope parameters if the same graph scales are used). The correlations for the sales and DPS variables were statistically significant at the 5 per cent level.

To see if the relationship between the data change and the slope parameter differed between the two performance groups, we split the graphs relating to each key financial variable into two sub-groups, based on the median data trend for that variable, and fitted a simple OLS regression model relating graph slope parameter (dependent variable) to data trend for each sub-group. In the case of all four key financial variable graphs, the slope of the regression line is greater for the 'poor performance' (i.e., below the median data trend) sub-group. The profit before tax and DPS regression slope coefficient estimates for the poor performance sub-group were significant at the 5 per cent level and for sales was significant at the 10 per cent level (i.e., there was a significant positive relationship between data increase and slope parameter). No significant regression slope coefficient estimates were found for the above median sub-group (i.e., there was no significant positive relationship between data increase and slope parameter). Thus, although poor performance is associated with a lower absolute slope parameter than good performance, the relationship is not uniformly linear. In essence, poor performance graphs have slope parameters which are higher relatively than those of good performance graphs.

Our findings concerning the wide variation in slope parameters in practice can be partly explained by the custom of using, as far as possible, standard proportions for the graphs of all key financial variables, especially when they are grouped together on a page. This design strategy, which gives a symmetrical visual impact, appeals to the eye. Thus graphs of the same width, and where possible the same height, are constructed by scaling the key financial variable to accommodate the data. Typically, sales, profit before tax, and EPS each use different scales (for example, \$million, $\$ 000$, and cents), thus facilitating graphs of equal height.

Unfortunately, this design strategy impairs communicative effectiveness, since all key financial graphs will have the same shape parameter. Associated slope parameters therefore vary depending on the data values. This may explain the observed high degree of dispersion in slope parameters. In the case of DPS, however, the unit of measurement is normally the same as that for EPS (indeed, commonly both variables appear on the same graph). Consequently DPS graphs will inevitably have smaller slope parameters than EPS graphs, since DPS is normally smaller than EPS. 


\section{SUMMARY AND CONCLUSIONS}

Research in statistical graphics provides theoretical and empirical support for the view that the judgmental accuracy of physical slopes is maximized at $45^{\circ}$. This value, in conjunction with the data values to be portrayed, determines the optimal shape parameter. Typically, experimental studies have used highly abstract test materials. In this article, the results of a laboratory study using realistic graphic stimuli provide strong evidence that, in the context of financial performance evaluation tasks, graph slope significantly affects both the specific conceptual categories which are used in reading graphs and the accuracy of comparative judgments. Our findings therefore contribute to the study of alternative presentations in financial reporting, indicating that sub-optimal slope parameters may produce distorted judgments of corporate financial performance by users. In particular, financial graphs with large slope parameters are likely to be perceived as portraying stronger growth than those with small slope parameters. Future research that varies design and construction characteristics of the graphs (e.g., use of labels, convexity/concavity of trend line) and the processing time allowed is required to assess the sensitivity of our results to different graphical scenarios.

Most large companies present graphs prominently in their corporate annual report and graphs are an important and potentially effective means of communicating financial information. Our empirical study of corporate practice reveals, however, that the majority of key financial graphs contained in corporate annual reports exhibit slope parameters which depart materially from the optimum. This finding is attributed partly to the use of design strategies which conflict with the use of the optimum slope parameter. Users' perceptions of corporate performance are thus likely to be distorted.

Given the significant distortion in perceptions that arises from sub-optimal slope parameters, we would recommend that regulations (or at least guidelines) be introduced to limit permitted slope parameters to an acceptable range (i.e., to prohibit extreme slope parameters that produce distorted judgments). Regulators in the U.K. have recently shown a willingness to endorse recommendations of this type (ASB, 2000, pp. 28-9).

\section{REFERENCES}

Abdel-Khalik, A. R., 'On the Efficiency of Subject Surrogation in Accounting Research', The Accounting Review, October 1974.

Anderson, R. H., and M. J. Epstein, The Usefulness of Corporate Annual Reports to Shareholders in Australia, New Zealand, and the United States: An International Comparison, JAI Press, 1996.

Arnold, J., and P. Moizer, 'A Survey of the Methods Used by U.K. Investment Analysts to Appraise Investments in Ordinary Shares', Accounting and Business Research, Summer 1984.

ASB, Year-End Financial Reports: Improving Communication, Discussion Paper, Accounting Standards Board, February 2000.

Ashton, R. H., and Kramer, S. S., 'Students as Surrogates in Behavioral Accounting Research: Some Evidence', Journal of Accounting Research, Vol. 18, No. 1, 1980.

Bartlett, S. A., and R. A. Chandler, 'The Corporate Report and the Private Shareholder: Lee and Tweedie Twenty Years On', British Accounting Review, September 1997. 
Bazerman, M. H., Judgment in Managerial Decision Making, Wiley, 1990.

Beattie, V. A., and M. J. Jones, The Communication of Information Using Graphs in Corporate Annual Reports, Certified Research Report 31, Chartered Association of Certified Accountants, Certified Accountants Educational Trust, 1992a.

— , 'The Use and Abuse of Graphs in Annual Reports: A Theoretical Framework and Empirical Study', Accounting and Business Research, Autumn 1992b.

—, Financial Graphs in Corporate Annual Reports: A Review of Practice in Six Countries, Research Report, Institute of Chartered Accountants in England and Wales, 1996.

- ' 'A Comparative Study of the Use of Financial Graphs in the Corporate Annual Reports of Major U.S. and U.K. Companies', Journal of International Financial Management and Accounting, Vol. 8, No. 1, 1997.

—, Graphical Reporting Choices: Communication or Manipulation?, Research Report 56, Chartered Association of Certified Accountants, Certified Accountants Educational Trust, 1998.

_- 'Australian Financial Graphs: An Empirical Study', Abacus, February 1999.

—_, 'Changing Graph Use in Corporate Annual Reports: A Time-Series Analysis', Contemporary Accounting Research, Summer, 2000.

Bertin, J., Semiology of Graphics: Diagrams, Networks and Maps, translated into English by W. J. Berg, University of Wisconsin Press, 1983.

Bettman, J. R., and P. Kakkar, 'Effects of Information Presentation Format on Consumer Information Acquisition Strategies', Journal of Consumer Research, March 1977.

Birnberg, J. G., L. Turopolec and S. M. Young, 'The Organizational Context of Accounting', Accounting, Organizations and Society, Vol. 8, Nos 2-3, 1983.

Blocher, E., R. P. Moffie and R. W. Zmud, 'Report Format and Task Complexity: Interaction in Risk Judgments', Accounting, Organizations and Society, 1986.

Canadian Institute of Chartered Accountants, Using Ratios and Graphics in Financial Reporting, CICA, 1993.

Clarke, T., and R. Bostock, 'Governance in Germany: The Foundations of Corporate Structure?', in K. Keasey, S. Thompson and M. Wright (eds), Corporate Governance: Economic, Management and Financial Issues, Oxford University Press, 1997.

Cleveland, W. S., 'A Model for Studying Display Methods of Statistical Graphics (With Discussion)', Journal of Computational and Statistical Graphics, Vol. 2, No. 4, 1993.

— The Elements of Graphing Data, rev. ed., Hobart Press, 1994.

Cleveland, W. S., and R. McGill, 'Graphical Perception: Theory, Experimentation and Application to the Development of Graphical Methods', Journal of the American Statistical Association, September, 1984.

_- 'Graphical Perception and Graphical Methods for Analyzing Scientific Data', Science, Vol. 229, 1985.

— ' 'Graphical Perception: The Visual Decoding of Quantitative Information on Graphical Displays of Data', Journal of the Royal Statistical Society, Vol. 150, No. 3, 1987.

Clevelend, W. S., R. McGill and M. E. McGill, 'The Shape Parameter of a Two-Variable Graph', Journal of the American Statistical Association, June 1988.

Courtis, J. K., 'Corporate Annual Report Graphical Communication in Hong Kong: Effective or Misleading?', The Journal of Business Communication, July 1997.

Davis, L. R., 'Report Format and the Decision-Maker's Task: An Experimental Investigation', Accounting, Organizations and Society, Vol. 14, Nos 5/6, 1989.

Department of Trade and Industry, Modern Company Law for a Competitive Economy: Developing the Framework, Consultation Document, Company Law Review Steering Group, March 2000.

DeSanctis, G., and S. L. Jarvenpaa, 'Graphical Investigation of Accounting Data for Financial Forecasting: An Experimental Investigation', Accounting, Organizations and Society, Vol. 14, Nos 5/6, 1989.

Epstein, M. J. and M. L. Pava, The Shareholder's Use of Corporate Annual Reports, JAI Press, 1993.

Financial Reporting Council, Annual Review 1998, FRC, 1999. 
Frownfelter, C. A., and C. L. Fulkerson, 'Linking the Incidence and Quality of Graphics in Annual Reports to Corporate Performance: An International Comparison', Advances in Accounting Information Systems, Vol. 6, 1998.

Gibbins, M., A. Richardson, and J. Waterhouse, 'The Management of Corporate Financial Disclosure: Opportunism, Ritualism, Policies and Processes', Journal of Accounting Research, Spring 1990.

- The Management of Financial Disclosure: Theory and Perspectives, Research Monograph Number 20, The Canadian Certified General Accountants' Research Foundation, 1992.

Graves, O. F., D. L. Flesher and R. E. Jordan, 'Pictures and the Bottom Line: The Television Epistemology of U.S. Annual Reports', Accounting, Organizations and Society, Vol. 21, No. 1, 1996.

Hall, A. S., The Construction of Graphs and Charts, Pitman, 1958.

Hofstedt, T. R., 'The Behavioural Parameters of Financial Analysis', The Accounting Review, October 1972.

Hollands, J. G., and I. Spence, 'Judgments of Change and Proportion in Graphical Perception', Human Factors, Vol. 34, No. 3, 1992.

Houghton, K. A., and J. J. F. Hronsky, 'The Sharing of Meaning Between Accounting Students and Members of the Accounting Profession', Accounting and Finance, November 1993.

Jarvenpaa, S. L., 'The Effects of Task Demand and Graphical Format on Information Processing Strategies', Management Science, Vol. 35, No. 3, 1989.

—_, 'Graphic Displays in Decision Making—the Visual Salience Effect', Journal of Behavioral Decision Making, Vol. 3, No. 4, 1990.

Kaplan, S. E., 'An Examination of the Effect of Presentation Format on Auditors' Expected Value Judgements', Accounting Horizons, September 1988.

Kosslyn, S. M., Elements of Graph Design, W. H. Freeman, 1994.

Lee T. A., and D. P. Tweedie, The Institutional Investor and Financial Information, Institute of Chartered Accountants in England and Wales, 1981.

Leivian, G. M., 'How to Communicate Financial Data More Efficiently', Management Accounting (U.S.A.), July 1980.

Libby, R., and B. L. Lewis, 'Human Information Processing Research in Accounting: The State of the Art', Accounting, Organizations and Society, Vol. 2, No. 3, 1977.

Mather, P., A. Ramsay and A. Serry, 'The Use and Representational Faithfulness of Graphs in Annual Reports: Australian Evidence', Australian Accounting Review, Vol. 6, No. 2, 1996.

Mather, P., A. Ramsay and A. Steen, 'The Use and Representational Faithfulness of Graphs in Australian IPO Prospectuses', Accounting, Auditing and Accountability Journal, Vol. 13, No. 1, 2000.

Preston, A. M., C. Wright and J. J. Young, 'Imag[in]ing Annual Reports', Accounting, Organizations and Society, Vol. 21, No. 1, 1996.

Remus, W., 'Graduate Students as Surrogates for Managers in Experiments on Business DecisionMaking', Journal of Business Research, Vol. 14, No. 1, 1986.

Revsine, L., 'The Selective Financial Misrepresentation Hypothesis', Accounting Horizons, December 1991.

SAS Institute, SAS/STAT User's Guide, Version 6, 4th ed., Volume 1, SAS Institute, 1989.

Schipper, K., 'Commentary on Earnings Management', Accounting Horizons, December 1989.

Schmid, C. F., Statistical Graphics: Design Principles and Practices, John Wiley/Interscience, 1983.

Simcox, W. A., 'A Method for Pragmatic Communication in Graphic Displays', Human Factors, August 1984.

Squiers, C., 'The Corporate Year in Pictures', reprinted in R. Bolton (ed.), The Contest of Meaning: Critical Histories of Photography, Massachusetts Institute of Technology, 1989.

Steinbart, P. J., 'The Auditor's Responsibility for the Accuracy of Graphs in Annual Reports: Some Evidence of the Need for Additional Guidance', Accounting Horizons, September 1989. 
Sullivan, J. J., 'Financial Presentation Format and Managerial Decision Making: Tables Versus Graphs', Management Communication Quarterly, Vol. 2, No. 2, 1988.

Swieringa, R. J., 'Some Comments About Research and the FASB', Behavioral Research in Accounting, Vol. 8, 1996.

Taylor, B. G., and L. K. Anderson, 'Misleading Graphs: Guidelines for the Accountant', Journal of Accountancy, October 1986.

Tufte, E. R., The Visual Display of Quantitative Information, Graphic Press, 1983.

Tversky, A., and D. Kahneman, 'The Framing of Decisions and the Rationality of Choice', Science, Vol. 211, 1981.

Tweedie, D., and G. Whittington, 'Financial Reporting: Current Problems and Their Implications for Systematic Reform', Accounting and Business Research, Winter 1990.

Von Huhn, R., 'A Trigonometrical Method for Computing the Scales of Statistical Charts to Improve Visualization', Journal of the American Statistical Association, 1931.

Watts, R. L., and J. L. Zimmerman, Positive Accounting Theory, Prentice-Hall, 1986.

_

\section{APPENDIX A}

\section{SAMPLE COLUMN GRAPH USED IN THE EXPERIMENT}
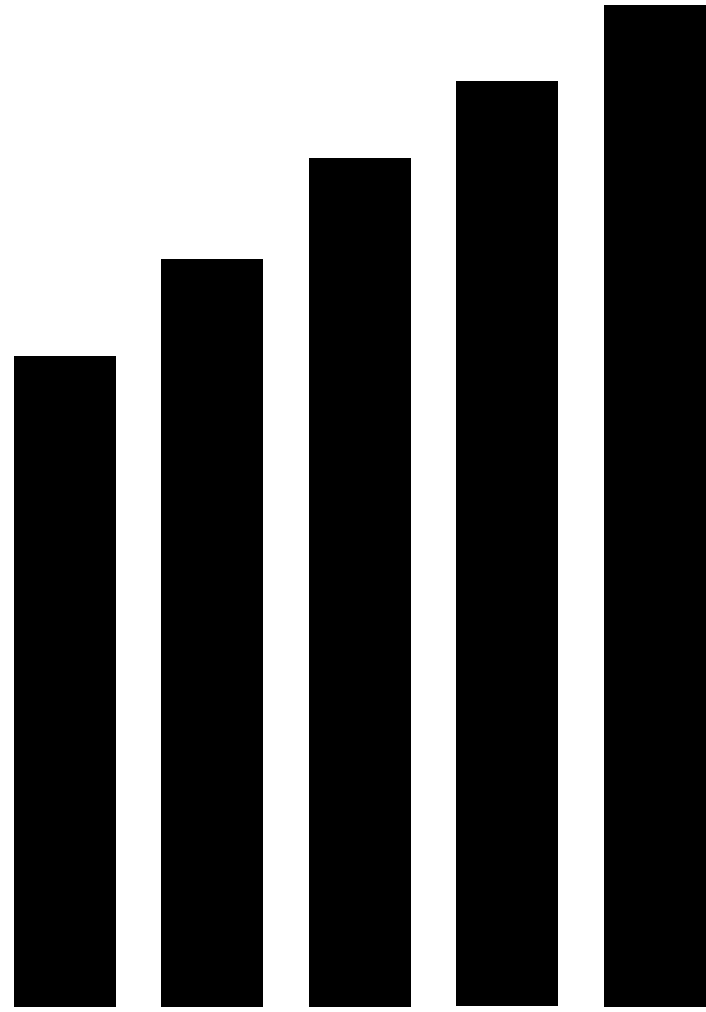


\section{APPENDIX B}

EXPERIMENT TWO: $T$-TESTS OF 18 PLANNED MATCHED TRIALS BETWEEN TRIAL GROUP X (NO SLOPE EFFECT) AND TRIAL GROUP Y (SLOPE EFFECT), WITH DATA CHANGES HELD CONSTANT ${ }^{\mathrm{a}}$

\begin{tabular}{|c|c|c|c|c|c|c|c|c|c|c|c|c|}
\hline \multirow[t]{4}{*}{ Column 1} & \multirow[t]{4}{*}{2} & \multirow{3}{*}{\multicolumn{3}{|c|}{$\begin{array}{cc}3 & 4 \\
& \text { Common data } \\
\text { for both trial } \\
\text { groups X and Y }\end{array}$}} & 6 & 7 & 8 & 9 & 10 & 11 & 12 & 13 \\
\hline & & & & & \multicolumn{2}{|c|}{ Data differs } & \multirow{3}{*}{$\begin{array}{c}\text { Trial groups } \\
\mathrm{X} \text { and } \mathrm{Y}\end{array}$} & \multirow{3}{*}{ Trial group Y } & \multirow{3}{*}{\multicolumn{3}{|c|}{ Test statistics }} & \\
\hline & & & & & $\begin{array}{c}\text { Trial } \\
\text { group X }\end{array}$ & $\begin{array}{c}\text { Trial } \\
\text { group Y }\end{array}$ & & & & & & \\
\hline & & \multicolumn{2}{|c|}{ Graph A } & Graph B & Graph B & Graph B & & & & & & \\
\hline $\begin{array}{l}\text { Comparison } \\
\text { no. }\end{array}$ & $\begin{array}{c}\text { Comparison of trial } \\
\text { nos. (trial group X } \\
\text { stated first) } \\
\text { (from Table 1) }\end{array}$ & $\begin{array}{c}\text { Data } \\
\text { change }\end{array}$ & $\begin{array}{c}\text { Slope } \\
\text { parameter }\end{array}$ & $\begin{array}{c}\text { Data } \\
\text { change }\end{array}$ & $\begin{array}{c}\text { Slope } \\
\text { parameter }\end{array}$ & $\begin{array}{c}\text { Slope } \\
\text { parameter }\end{array}$ & $\begin{array}{c}\text { Common data } \\
\text { change difference } \\
\text { (graph A-graph B) } \\
\text { (col.3-col.5) }\end{array}$ & $\begin{array}{c}\text { Slope parameter } \\
\text { difference in trial Y } \\
\text { (graph A-graph B) } \\
\text { (col.4-col.7) }\end{array}$ & 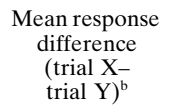 & $t$-statistic & $\begin{array}{l}\text { Expected } \\
\text { sign of } \\
\text { mean } \\
\text { difference }\end{array}$ & Prob. \\
\hline 1 & $4 \& 5$ & $100 \%$ & $30^{\circ}$ & $50 \%$ & $30^{\circ}$ & $45^{\circ}$ & $50 \%$ & $-15^{\circ}$ & -0.189 & -1.278 & - & 0.103 \\
\hline 2 & $19 \& 20$ & $200 \%$ & $30^{\circ}$ & $100 \%$ & $30^{\circ}$ & $45^{\circ}$ & $100 \%$ & $-15^{\circ}$ & -0.377 & -2.266 & - & $0.013^{*}$ \\
\hline 3 & $16 \& 17$ & $200 \%$ & $30^{\circ}$ & $50 \%$ & $30^{\circ}$ & $45^{\circ}$ & $150 \%$ & $-15^{\circ}$ & $0.075^{\mathrm{c}}$ & 0.496 & - & 0.310 \\
\hline 4 & $8 \& 7$ & $100 \%$ & $45^{\circ}$ & $50 \%$ & $45^{\circ}$ & $30^{\circ}$ & $50 \%$ & $15^{\circ}$ & 0.302 & 2.934 & + & $0.002 * *$ \\
\hline 5 & $26 \& 25$ & $200 \%$ & $45^{\circ}$ & $100 \%$ & $45^{\circ}$ & $30^{\circ}$ & $100 \%$ & $15^{\circ}$ & 0.056 & 0.323 & + & 0.374 \\
\hline 6 & $23 \& 22$ & $200 \%$ & $45^{\circ}$ & $50 \%$ & $45^{\circ}$ & $30^{\circ}$ & $150 \%$ & $15^{\circ}$ & 0.132 & 0.980 & + & 0.166 \\
\hline 7 & $8 \& 9$ & $100 \%$ & $45^{\circ}$ & $50 \%$ & $45^{\circ}$ & $70^{\circ}$ & $50 \%$ & $-25^{\circ}$ & -0.151 & -1.033 & - & 0.153 \\
\hline 8 & $26 \& 27$ & $200 \%$ & $45^{\circ}$ & $100 \%$ & $45^{\circ}$ & $70^{\circ}$ & $100 \%$ & $-25^{\circ}$ & -0.170 & -1.137 & - & 0.130 \\
\hline 9 & $23 \& 24$ & $200 \%$ & $45^{\circ}$ & $50 \%$ & $45^{\circ}$ & $70^{\circ}$ & $150 \%$ & $-25^{\circ}$ & -0.377 & -2.017 & - & $0.024 *$ \\
\hline 10 & $13 \& 12$ & $100 \%$ & $70^{\circ}$ & $50 \%$ & $70^{\circ}$ & $45^{\circ}$ & $50 \%$ & $25^{\circ}$ & 0.453 & 2.946 & + & $0.002 * *$ \\
\hline 11 & $34 \& 33$ & $200 \%$ & $70^{\circ}$ & $100 \%$ & $70^{\circ}$ & $45^{\circ}$ & $100 \%$ & $25^{\circ}$ & 0.377 & 2.430 & + & $0.009 * *$ \\
\hline 12 & $31 \& 30$ & $200 \%$ & $70^{\circ}$ & $50 \%$ & $70^{\circ}$ & $45^{\circ}$ & $150 \%$ & $25^{\circ}$ & 0.000 & 0.000 & + & 0.500 \\
\hline 13 & $4 \& 6$ & $100 \%$ & $30^{\circ}$ & $50 \%$ & $30^{\circ}$ & $70^{\circ}$ & $50 \%$ & $-40^{\circ}$ & -0.208 & -1.261 & - & 0.101 \\
\hline 14 & $19 \& 21$ & $200 \%$ & $30^{\circ}$ & $100 \%$ & $30^{\circ}$ & $70^{\circ}$ & $100 \%$ & $-40^{\circ}$ & -0.755 & -3.650 & - & $0.000 * *$ \\
\hline 15 & $16 \& 18$ & $200 \%$ & $30^{\circ}$ & $50 \%$ & $30^{\circ}$ & $70^{\circ}$ & $150 \%$ & $-40^{\circ}$ & -0.321 & -1.553 & - & 0.063 \\
\hline 16 & $13 \& 11$ & $100 \%$ & $70^{\circ}$ & $50 \%$ & $70^{\circ}$ & $30^{\circ}$ & $50 \%$ & $40^{\circ}$ & 0.340 & 2.475 & + & $0.008^{* *}$ \\
\hline 17 & $34 \& 32$ & $200 \%$ & $70^{\circ}$ & $100 \%$ & $70^{\circ}$ & $30^{\circ}$ & $100 \%$ & $40^{\circ}$ & 0.377 & 2.360 & + & $0.011 *$ \\
\hline 18 & $31 \& 29$ & $200 \%$ & $70^{\circ}$ & $50 \%$ & $70^{\circ}$ & $30^{\circ}$ & $150 \%$ & $40^{\circ}$ & 0.358 & 2.657 & + & $0.005^{* *}$ \\
\hline
\end{tabular}

a Columns 3-5 present the three data items that are common to trial groups $\mathrm{X}$ and $\mathrm{Y}$. Columns 6-7 highlight the differing slope parameters for graph B, the critical point of difference between the two trial groups $\mathrm{X}$ and $\mathrm{Y}$. Column 8 shows the data change difference between graphs $\mathrm{A}$ and $\mathrm{B}$ common to both trial groups (col.3 less col.5), while column 9 indicates the slope parameter difference between graphs A and B for trial group Y (col.4 less col.7). Finally, columns 10-13 present the test statistics. The results are ordered in increasing absolute

slope parameter difference order (see col.9).
$b$ In a few cases, the mean response differences vary from those deducible from Table 1 due to the different treatment of missing values.

* Significant at 0.05 level (one-tailed); ** Significant at 0.01 level (one-tailed). 